\title{
COVID-19: the physician's response in the first phase
}

\section{DOI: $10.7861 /$ clinmed.ed.20.3.1}

For most physicians, as 2020 dawned there was no indication that a pandemic illness would transform the face of healthcare within a dramatically short timeframe: today there is no indication of when we will 'return to normal'. Most wisdom leans towards the notion that the old normal is over. Dealing with tumultuous change is famously stressful; dealing with it while uncertain of the safety of one's loved ones, while acting out of one's main area of expertise and while feeling somewhat helpless is especially arduous. The medical community has responded in a spectacular and unambiguous way, and for all readers their exhaustion and dedication has been matched by the humbling sense of being part of an extraordinary local and global response.

For clinicians to have responded so, while also advising patient charities, specialist societies and healthcare leaders is particularly noteworthy. We are delighted, therefore, that this edition of Clinical Medicine showcases the outputs from many of those national specialist associations. That these are UK societies is not to suggest some notion of British exceptionalism - similar efforts have emerged from many nations; but there is a large amount of practical advice for non-specialist physicians from respiratory, cardiovascular, neurology and rheumatology colleagues. ${ }^{1-4}$ In addition we are pleased to highlight brief practical approaches to acute supportive care and nutrition. ., $^{2}$ These are not intended as definitive guidelines - how could there be such for a rapidly changing disease with highly variable outcomes? - but as prompts of rapidly-learned best practice. The intention of all these pieces has one common feature: to share the learnings from one group of patients to inform the care of future ones. If there is a piece that exemplifies that message it is the one by Andrew Davies and Jo Hayes on palliative care issues raised by the pandemic; the impact on patients, staff and services is elegantly depicted. ${ }^{7}$

Beyond the immediate clinical issues, physicians are expected to be informed about and share opinions on COVID-19-related issues, such as testing and personal protective equipment (PPE). The policy of the Royal College of Physicians has been twofold, to push for clarity of message and for the best interests of patients and its members with these issues. As a journal, we are keen to reflect the views and practice of clinicians and are pleased to include experiential peer-reviewed pieces by Hill et al on drivethrough testing and by Thomas et al on the practicalities of the NHS England PPE guidance. ${ }^{8,9}$ The COVID-19 pandemic will plainly have repercussions on the healthcare needs of the population, and hence the way services are provided; these will be the subject of much of the next edition of Clinical Medicine. Marrying up these demands with the pre-pandemic challenge to deliver personalised healthcare is the subject of a manuscript by Fernandes et al. ${ }^{10}$ And, beyond COVID-19, this edition of the journal has the usual mix of interesting original research - to highlight a piece on non-alcoholic fatty liver disease and cirrhosis and on the impact of the Tracey judgment on outcomes of in-hospital cardiac arrests. ${ }^{11,12}$ There is no CME section this month, due to inclusion of pandemic-related content, but this omission will be only temporary.

The urgency to disseminate current COVID-19-related findings has been aided by the online availability of journal content. Not only does this allow early publishing, but also increases the breadth of what is available in the print form of the journal. The online content includes several uniquely online articles and case histories (to highlight one in particular, https://doi.org/10.7861/clinmed.2020-0123). All this content is collated and freely available at www.rcpjournals.org/ covid-19: please do access it, and if there are glaring areas of omission, please contact me directly with your thoughts. The generosity of physicians at this time has extended beyond just their clinical duties to also include their willingness to author and peer-review material. For this, and for everything else you are involved with, many thanks, and best wishes for your good health from all in the RCP journals team.

\section{References}

1 Bennett J, Munavvar M, Walker P, Phillips G. Respiratory advice for the non-respiratory physician in the time of COVID-19. Clin Med 2020;20:251-5.

2 Davis GK, Adlan A, Majewski J, Ibrahim B. SARS-CoV-2 pandemic and the cardiovascular system: What the non-cardiologist needs to know. Clin Med 2020;20:262-5.

3 Mummery C], Kipps C. UK neurology response to the COVID-19 crisis. Clin Med 2020;20:266-9.

4 Price E, MacPhie E, Kay L et al. Identifying rheumatic disease patients at high risk and requiring shielding during the COVID-19 pandemic. Clin Med 2020;20:256-61.

5 Goyal DK, Mansab F, Iqbal A, Bhatti S. Early intervention improves mortality in COVID-19 infection. Clin Med 2020;20:248-50.

6 Mehta S. Nutritional status and COVID-19: an opportunity for lasting change? Clin Med 2020;20:270-3.

7 Davies A, Hayes J. Palliative care in the context of a pandemic: similar but different. Clin Med 2020;20:274-7.

8 Hill K, Campbell R, Mutch C, Koch O, Mackintosh C. Drive-through testing in COVID-19: experience from NHS Lothian. Clin Med 2020;20:290-1.

9 Thomas JP, Srinivasan A, Wickramarachchi CS et al. Evaluating the national PPE guidance for NHS healthcare workers during the COVID-19 pandemic. Clin Med 2020;20:242-7.

10 Fernandes L, FitzPatrick M, Roycroft M. The role of the future physician: Building on shifting sands. Clin Med 2020;20:285-9.

11 Hussain A, Patel PJ, Rhodes F et al. Decompensated cirrhosis is the commonest presentation for NAFLD patients undergoing liver transplant assessment. Clin Med 2020;20:313-8.

12 Zenasni Z, Reynolds EC, Harrison DA et al. The impact of the Tracey judgment on the rates and outcomes of in-hospital cardiac arrests in UK hospitals participating in the National Cardiac Arrest Audit. Clin Med 2020;20:319-23.

Anton Emmanuel Editor-in-chief

$\begin{array}{lllll}\text { Members of the editorial board } & & \\ \text { Cono Ariti } & \text { Albert Edwards } & \text { Alexandra Lake } & \text { Gerrard Phillips } & \text { Trainee associate editors: } \\ \text { Paul Belcher } & \text { Anton Emmanuel } & \text { Yash Mahida } & \text { Sushma Saksena } & \text { Tessa Cacciottolo } \\ \text { Rodger Charlton } & \text { Kate Evans } & \text { Nick Manning-Cork } & \text { Philip Smith } & \text { Rajan Pooni } \\ \text { Tim Chevassut } & \text { Laura Ferrigan } & \text { Chris Marguerie } & \text { Angela Star } & \text { Anenta Ramakrishnan } \\ \text { Tahseen Chowdhury } & \text { Tevfik Ismail } & \text { Martin McKee } & \text { Cameron Swift } & \\ \text { Richard Corbett } & \text { Vikas Kapil } & \text { Andrew Medford } & \text { Rhys Thomas } & \\ \text { Elaine Dennison } & \text { Neelam Kumar } & \text { Mehool Patel } & & \end{array}$

